\title{
El impacto comparado de las políticas de transparencia en los procesos democráticos de Chile y Colombia en el primer cuarto del siglo XXI*
}

\author{
Daniel Del Castillo-Rengifo** \\ Université Paris 1 Panthéon-Sorbonne, Francia \\ Mario Carvajal-Cabal $* * *$ \\ Pontificia Universidad Javeriana, Colombia \\ https://doi.org/10.15446/frdcp.n21.86339
}

\section{Resumen}

En este artículo se estudia la corrupción como un problema político cuyo análisis se debe realizar acorde a las categorías conceptuales de la ciencia política y de todas las áreas de las ciencias sociales. Los aportes de la ciencia política a la investigación sobre el fenómeno de la corrupción se establecen en la tipología que mejor se adapta a sus últimas evoluciones y permiten comprenderlo más allá de la tradicional distinción público/

\footnotetext{
* Artículo recibido: $1^{\circ}$ de febrero de 2021 / Aceptado: 3 de agosto de 2021 / Modificado: 21 de agosto de 2021. Este artículo es producto de una investigación titulada "El impacto comparado de las políticas de transparencia en los procesos democráticos chileno y colombiano: primer cuarto del siglo XXI” basada en una revisión bibliográfica, así como un estado de la cuestión, sobre la corrupción para obtener el título profesional. No contó con financiación para su realización.

** Politólogo de la Université Paris 1 Panthéon-Sorbonne, Francia, especialista en Procesos Políticos Latinoamericanos por Clacso, Argentina. Líder de Transparencia de la Secretaría Distrital de Gobierno de Bogotá, Colombia. Correo electrónico: danielpolitics@icloud.com iD https://orcid.org/0000-0002-6496-0022 *** Internacionalista de la Pontificia Universidad Javeriana, Colombia, candidato a magíster en Estudios Latinoamericanos de University of Oxford, Reino Unido. Asistente de Investigación en Greenmantle, Colombia. Correo electrónico: mariocarvajal9@gmail.com (iD https://orcid.org/0000-0003-0879-3087
}

\section{Cómo citar}

Del Castillo-Rengifo, D. y Carvajal-Cabal, M. (2022). El impacto comparado de las políticas de transparencia en los procesos democráticos de Chile y Colombia en el primer cuarto del siglo XXI. FORUM. Revista Departamento Ciencia Política, 21, 198-227. https://doi.org/10.15446/frdcp.n21.86339 
privado, hoy en día obsoleta. A través de un análisis comparativo realizado con estudios de caso en la materia para Chile y Colombia, los lectores podrán adquirir una visión integral del fenómeno de la corrupción en Latinoamérica. Así mismo, evaluaremos las políticas de transparencia en estos países, desde un enfoque ciudadano y de cambio cultural.

Palabras clave: corrupción política; América Latina; democracia; ética; sociedad civil.

\title{
Transparency Policies on the Chilean and Colombian Democratic Processes in the First Quarter of the $21^{\text {st }}$ Century: A Comparative Impact Study
}

\begin{abstract}
Corruption is a political problem; hence its analysis relies on conceptual categories of political science, and all social sciences. Political science's contributions to research on the phenomenon of corruption are established in the typology that best adapts to its latest evolutions and allow us to understand it beyond the traditional public / private distinction, nowadays obsolete. Through a comparative analysis carried out with case studies for Chile and Colombia, readers will be able to acquire a comprehensive vision of the phenomenon of corruption in Latin America. Additionally, we will evaluate transparency policies in these countries from a citizen and cultural change point of view.
\end{abstract}

Keywords: political corruption; Latin America; democracy; ethics; civil society.

\section{El proceso democrático de Chile y Colombia en el primer cuarto del siglo XXI}

Se viven tiempos de debilidad de las instituciones democráticas. Analistas como Lynch (2009) y Monedero (2019) dialogan sobre este punto. Objeto de una crisis múltiple - de legitimidad, autoridad, confianza e independencia- que afecta el núcleo de sus valores originales y fundadores, la democracia en América Latina está exhausta.

En cuanto al proceso democrático chileno, si bien se puede observar la dictadura de Pinochet (1973-1990), desde los años de 1990 se produce un restablecimiento de la democracia que permitió a la sociedad política realizar una reconciliación ${ }^{1}$. El profesor chileno Carlos Ominami (2018) resalta los antecedentes primordiales de la reconciliación chilena como lo

\footnotetext{
1. La reconciliación es uno de los pilares del peacebuilding. Ahora bien, Ominami (2018) recuerda que Allende fue el primero en proponer una vía pacífica al socialismo, pero esta experiencia fue ahogada por Pinochet, con el apoyo de los Estados Unidos.
} 
son el dinamismo económico, el restablecimiento del Estado de Derecho y la protección de los Derechos Humanos. La transición democrática chilena estuvo marcada por una economía dinámica que frenó el modelo neoliberal en varios aspectos sociales como el incremento del salario mínimo, mejores condiciones legales para los sindicatos y la lucha contra la pobreza. Estos antecedentes tienen repercusiones que todavía hoy se ven en Chile, por ejemplo, con una población menos numerosa que en Colombia en términos de pobreza extrema².

En particular, Ominami (2018) recuerda que hubo una Comisión de Verdad y Reconciliación donde se conocieron las graves violaciones a los Derechos Humanos durante el régimen militar. El Estado pidió disculpas. Se dieron beneficios a los desaparecidos y a las víctimas. En Colombia, la Comisión para el Esclarecimiento de la Verdad, la Convivencia y la No Repetición fue instalada en 2018, producto del Acuerdo de Paz firmado entre el gobierno del presidente Juan Manuel Santos y las Fuerzas Armadas Revolucionarias de Colombia - Ejército del Pueblo (FARC-EP) en 2016. En una sociedad profundamente conservadora, marcada por una cultura política clientelista, este Acuerdo ha enfrentando una agresiva serie de escollos políticos, que crearon un clima de desconfianza y finalmente terminaron en el rearme de una disidencia de alrededor de 2,300 miembros de las FARC-EP hacia agosto de 2019 (Unidad Investigativa, 2020). Por ende, la restauración de la derecha en Colombia se plantea como un desafío para varios de los comisionados ("La Comisión de la verdad va a rescatar la fe del país en el acuerdo de paz": Alfredo Molano, 2018), llegando incluso el comisionado presidente Francisco de Roux a preguntarse: "por qué la resistencia a reconocer seriamente responsabilidades de muchos participantes directos o indirectos en el conflicto? [...] ¿por qué las instituciones del Estado no asumen unidas la oportunidad de la paz grande, más allá de los partidos y de las rivalidades personales?" (15 reflexiones de Francisco de Roux en seis meses de búsqueda de la verdad, 2019). A pesar de la oportunidad histórica, la sociedad colombiana no se ha reconciliado. Se vuelve a un Estado de opinión donde se desarrolla una tiranía de las mayorías, mayorías además con un nivel de educación bajo³ . Robert Dahl clasificaría a

2. Según el Informe Banco Mundial (2018a), Chile cuenta con tan solo $1.3 \%$ de su población en condiciones de pobreza extrema. El mismo indicador sube a $4.5 \%$ para Colombia. En otras palabras, la corrupción tiene una correlación con la pobreza, porque esconde mecanismos que favorecen la desigualdad y el desempleo e impiden el desarrollo, que son caminos que conducen a la pobreza.

3. Según el Sistema Nacional de Información de la Educación Superior de Colombia, entre 2017 y 2018 la cantidad de estudiantes matriculados en la educación superior disminuyó. Entre 2016 y 2017, la caída en el acceso a la educación superior privada es del 10 \%, y a la educación pública de casi el 5 \%. Por otro lado, la desigualdad en el acceso es flagrante en Colombia, respecto a los departamentos periféricos: tan solo 189 estudiantes del Vaupés accedieron a la educación superior, mientras que Bogotá concentra el mayor acceso. Mientras los jóvenes confían cada vez menos en los beneficios de la educación, las matrículas en el sector privado no cesan de aumentar. Los datos se pueden observar en la página del Ministerio de Educación (Ministerio de Educación de Colombia -SNIES, s.f.). 
Colombia como una oligarquía competitiva, "con un alto grado de liberalización política pero con baja participación" (Dahl, citado en Del Castillo, 2019, p. 221), sobre todo una democracia incapaz en el estado actual de alcanzar ningún tipo de consenso político.

Sin duda alguna, la falta de consenso apunta hacia la incertidumbre y fuerte inestabilidad políticas que reinan actualmente en Colombia. Es de resaltar que, en Chile, la coalición política llamada la Concertación permitió gobernar al país durante 20 años (1990-2010)4 marcando una profunda continuidad y estabilidad política. Este proceso histórico se analiza como una recuperación de la democracia en Chile y como un cambio de lo que era Chile en la Dictadura.

Desde 2010, en Chile sucede algo similar a lo que sucedía en Colombia con el Frente Nacional (1958-1974): una repartición del poder entre el socialismo y la derecha moderada. No obstante, los errores acumulados del progresismo chileno, que no son un caso aislado en el mundo, sino que hacen parte de la tendencia mundial ${ }^{5}$ crearon una polarización demasiado alta en la sociedad. Desde el punto de vista de la historia democrática chilena, el ascenso de Piñera fue inevitable desde el 2009.

Pero en 2017 la coyuntura política y social es distinta. Mientras que la unión de la derecha consolidó el liderazgo de Piñera, la izquierda se encuentra cada vez más dividida. En particular, por el surgimiento de un partido de "tercera vía", producto de las movilizaciones sociales, el Frente Amplio. Carlos Ominami afirma que los electores del ala izquierdista le dieron su voto de confianza a Piñera en la segunda vuelta. Mientras tanto, el descontento ha seguido aumentando y "los discursos del crecimiento, el empleo y la mano dura frente a la delincuencia" (2018, p. 10) calan mejor en la sociedad hoy en día. No solamente el ascenso de Piñera era inevitable, sino que ahora su mandato se prolongó hasta 2022, algo que Ominami predijo desde 2018 (2018, p. 7).

Tanto en Chile como en Colombia, los escándalos de corrupción asociada con la izquierda progresista fraguaron el camino de la derecha. La corrupción es entonces un problema mayor que se inscribe en la historiografía reciente de la democracia de estas dos naciones. Pero no solamente esto, sino que se encuentra vigente. En efecto, ya desde el progresismo de Bachelet y de Santos, tanto Chile como Colombia venían adelantando políticas de contención de la corrupción.

\footnotetext{
4. Los presidentes durante la Concertación fueron: Patricio Alwyn (1990-1994), Eduardo Frei Ruiz-Tagle (1994-2000), Ricardo Lagos (2000-2006) y Michelle Bachelet (2006-2010; 2014-2018). Entre 2010 y 2014 gobierna el centro derecha de Sebastián Piñera. A partir del 2014, se forma la Nueva Mayoría y hasta 2018 ésta consolidó la coalición oficialista. 5. Esta tendencia también se observa en los Estados Unidos, Argentina y Perú.
} 
Por lo tanto, llegado a este primer cuarto del siglo XXI, se hace relevante analizar el impacto que han tenido estas políticas en el proceso democrático de Chile y Colombia. Además, la evaluación de impacto garantiza la transparencia y la rendición de cuentas (Medina, 2005). Estas son dos naciones latinoamericanas comparables en términos democráticos - por tratarse de regímenes presidencialistas-y de avance económico; si bien sus marcos legales no son tan similares, y además Chile es usualmente presentado como un campeón de la anti corrupción, asunto que en Colombia está lejos de ser el caso.

Así las cosas, existen antecedentes suficientes apuntando hacia la necesidad de ahondar en el problema de la corrupción en estos dos países desde un enfoque comparativo, a partir de las recomendaciones formuladas por las fuentes consultadas. Los estudios de Newman y Ángel (2017), así como de Valdivieso et al. (2014) comparten los siguientes puntos:

1. La presentación de la normatividad vigente y de los últimos impulsos en materia normativa.

2. El análisis de los problemas que atañen al fenómeno de la corrupción en Chile y Colombia, como son: el incremento de la delincuencia ${ }^{6}$, la implementación local de políticas, las condiciones socio-económicas que favorecen el fenómeno y la percepción de la corrupción en aumento.

3. El análisis de las propuestas programáticas para responder al fenómeno y buscar contrarrestarlo. En el caso de Newman y Ángel (2017), este análisis es comparativo a nivel latinoamericano.

\section{El contexto legal contra la corrupción en Chile y Colombia ${ }^{7}$}

El marco normativo de Colombia en materia de prevención y lucha contra la corrupción está compuesto por un robusto cuerpo de leyes, decretos y resoluciones ${ }^{8}$ que toman impulso desde el Estatuto Anticorrupción, la denominada Ley 1474 de $2011^{9}$,

6. Lo cual probablemente está relacionado con aquello que Robert A. Dahl llama la capacitación social sobre la norma: "la capacitación social sobre la norma (conocerla, saber sus causas y consecuencias, conocer sus implicaciones socio-políticas, etc.) mejora una obtención del consenso. El autor distingue tres tipos de capacitación social sobre la norma: la favorable o reforzadora, la compatible y la negativa" (Dahl, 1994).

7. Este apartado no tiene como objetivo realizar un análisis comparativo profundo de la jurisprudencia chilena y colombiana, sino realizar una presentación de los marcos jurídicos que corresponden al análisis del problema tratado en el presente trabajo. Al respecto, Newman y Ángel (2017) reconocen diferencias fundamentales entre Chile y Colombia en la coordinación interinstitucional y la regulación del cabildeo.

8. El marco normativo completo se puede consultar en español en las páginas de la Secretaría de Transparencia y del Observatorio de Transparencia y Anticorrupción.

9. Ley 1474 (2011) -Estatuto Anticorrupción- por la cual se dictan normas orientadas a fortalecer los mecanismos de prevención, investigación y sanción de actos de corrupción y la efectividad del control de la gestión pública. Artículos 62, 69 y 72 al 76. 
promulgada bajo el primer mandato presidencial de Juan Manuel Santos (2010-2014). Anteriormente a esta década, ya Colombia contaba con una serie de normas de suma relevancia, principalmente en materia penal y disciplinaria. En lo disciplinario, desde la Ley 87 de 1993 se estableció el Sistema de Control Interno de Colombia ${ }^{10}$. Igualmente, el desarrollo legislativo colombiano permite contar desde los años noventa con distintas normativas en materia fiscal (Ley 610, 2000) y de contratación pública (Ley 80, 1993).

Sin embargo, durante los dos gobiernos del presidente Juan Manuel Santos (20102018), se da un impulso normativo importante alrededor del mencionado Estatuto Anticorrupción, pero también de la Ley de Transparencia y del Derecho de Acceso a la Información Pública (Ley 1712, 2014); así como del Estatuto de Participación Ciudadana (Ley 1757, 2015). En particular, estas dos últimas regulaciones garantizan como Derecho Fundamental estos principios rectores de la prevención y lucha contra la corrupción que son la transparencia, el acceso a la información pública y la participación ciudadana ${ }^{11}$.

Aunado a lo anterior, también se toman disposiciones en materia de responsabilidad de las personas jurídicas por actos de corrupción transnacional, con la Ley 1778 $(2016)^{12}$. Finalmente, en el marco del posconflicto, el Decreto 1829 (2017) crea el Sistema Integrado de Información para el Posconflicto (SIIPO) de transparencia para la administración de los recursos de la cooperación internacional orientados a la construcción de una paz sostenible y duradera en Colombia.

Existe un marco normativo complementario relativo a dos temáticas específicas propias de dos desarrollos del país. Primero, el marco normativo relativo a los temas de Justicia Abierta, que se presenta como un desarrollo necesario e irreversible en la rama judicial en Colombia. Tanto la Constitución Política de Colombia de 1991, como la Ley Estatutaria de la Administración de Justicia, coronan el marco jurídico vigente en materia de principios y reglas de transparencia. Segundo, los lineamientos que derivan de las recomendaciones de la Alianza para el Gobierno Abierto (AGA), en la cual participa Colombia desde 2011.

10. Al respecto, la OCDE (2017; 2018a; 2018b; 2018c) resalta la inclusión de gestión de los riesgos de fraude y corrupción en los estándares de control interno tanto de Colombia, como de Chile.

11. Resaltan otras normas de participación ciudadana, como la Ley 134 de 1994 la cual regula los Mecanismos de Participación Ciudadana definidos en el Artículo 103 de la Constitución colombiana; y la Ley 850 de 2003, que reglamenta las veedurías ciudadanas. A este robustecido cuerpo normativo, se agregan disposiciones principales en temas como el Plan Anticorrupción y de Atención al Ciudadano, y las Comisiones Regionales de Moralización con el Decreto 1081 de 2015, y los decretos posteriores de 2017.

12. Se reglamentó esta Ley a través de la Resolución 100-002657 del 25 de julio de 2016, por medio de la cual se busca el fortalecimiento de los programas de compliance en el sector privado. La Circular Externa 100000003 de la Superintendencia de Sociedades contiene las instrucciones administrativas relacionadas con la promoción de programas de transparencia y ética empresarial, así como de los mecanismos internos de auditoría, anticorrupción y prevención del soborno transnacional, en el contexto de esta Ley (Ley 1778, 2016). 
Chile no se queda atrás en materia disciplinaria y penal, e incluso va más allá de Colombia en materia de regulación del lobby, con la Ley 20730 en la materia. El tema toma relevancia desde el 2008 con la Ley de Transparencia y Acceso a la Información Pública (Ley 20285, 2008) impulsada por Bachelet dentro del marco del ingreso de Chile a la OCDE en 2010. También cuentan con un robusto marco normativo en materia de responsabilidad de las personas jurídicas con la Ley 20393 (OCDE, 2021) 13 y también participan en la AGA desde 2011. Se puede inferir que Colombia ha seguido el mismo camino de Chile, en el camino de acceso a la OCDE, puesto que obtuvo en 2018.

Ahora bien, desde un enfoque comparativo, resulta pertinente preguntarnos si España constituye un tercer estudio de caso de referencia, en cuanto su cultura jurídica pudo influenciar históricamente aquellos de los dos casos latinoamericanos estudiados. El ordenamiento jurídico español en transparencia en la administración pública y anticorrupción se dio ya entrado el siglo XX, como lo expone Palomares (2016). El autor afirma que, antes de la entrada en vigor de la Ley 19 de 2013 de Transparencia, Acceso a la Información Pública y Buen Gobierno (LTBG):

[...] la aplicación de la transparencia para erradicar cada una de estas urdimbres corruptas durante el siglo XX ha tenido un denominador común, que se ha aplicado por los fiscales, jueces y Policía Judicial a fuerza de procedimientos judiciales dada la ausencia de preceptos que obligasen a rendir cuentas fidedignas de cada ápice de gestión de los dineros públicos, sin olvidar la encomiable labor del cuarto poder, los medios. (Palomares, 2016, p. 8)

En este sentido, los avances del Estado español en materia de transparencia se han dado a partir de los grandes escándalos de corrupción en el país, luego de los cuales son las autoridades judiciales las que se han encargado de reformar las leyes acorde a los ilícitos cometidos. El papel preponderante que ha jugado el estamento judicial o policivo no permite pensar en un referente de base, pues las democracias modernas latinoamericanas han demostrado ser pioneras en materia de transparencia y prevención, apuntado con mayor peso a cambiar la actitud y el accionar de la ciudadanía frente a los recursos públicos.

Así las cosas, vale la pena preguntarse ¿qué impacto han tenido las políticas de transparencia en Chile y Colombia en los procesos democráticos chileno y colombiano del primer cuarto del siglo XXI?

13. OECD. (2021, March 24). Enhancing economic performance and well being in Chile: Policy Actions for a more dynamic telecommunication sector. Retrieved from https://www.oecd.org/economy/surveys/CHL OECD_policy_actions_dynamic_telecommunication_sector.pdf 


\section{Elementos de metodología}

La metodología de investigación escogida es una metodología combinada, con orientación crítica. En efecto, la metodología cuantitativa - como se observa más adelante- ya demuestra fuertes contrastes entre los resultados en términos, por ejemplo, de pobreza y de percepción de la corrupción en estas dos democracias regionales. Una metodología de tipo cualitativa complementa el análisis anterior, y profundiza el cómo y el por qué del contraste en el impacto de las políticas de transparencia colombiana y chilena. Así mismo, permite ir más allá en la interpretación y el análisis de este impacto en términos democráticos para Latinoamérica, entrado este siglo XXI. Se analizaron y tomaron en cuenta diversidad de fuentes de tipo secundario, estadísticas de fuentes secundarias e informes de organizaciones internacionales.

No obstante, se tomaron estadísticas de las fuentes indirectas consultadas. Los índices trabajados son de Newman y Ángel (2017), "el Índice de Gobierno Abierto (IGA) de la Procuraduría General de la Nación y el Índice de Transparencia Departamental (ITD) de Transparencia por Colombia" (p. 25); así como el "índice de Transparencia de las Entidades Públicas (ITEP), los índices nacional (ITN) y departamental (ITD)" (Transparencia por Colombia, 2015, p. 37) ${ }^{14}$.

La orientación crítica parte del análisis en cuanto a los límites del enfoque normativo de lucha contra la corrupción, lo que indica un mayor impacto del enfoque preventivo de la corrupción. Pero también nace del análisis del impacto - tanto institucional, como cultural y político - de las medidas de transparencia en las democracias chilena y colombiana, así como en la democracia latinoamericana en este primer cuarto del siglo XXI.

Se realizó un estudio argumentativo de fuentes especializadas tomando como base varios informes de la OCDE. En particular, el Estudio de la OCDE (2017) sobre integridad en Colombia que propende por el establecimiento de "un sistema coherente y completo de integridad pública en Colombia" (p. 13). También se consultó un informe del Banco Mundial (2018a) y otro de la Alianza para el Gobierno Abierto (2017); así como artículos teóricos y científicos tomados de revistas especializadas; y algunos artículos analíticos tomados de la prensa reciente. La principal herramienta será la interpretación, la argumentación construida, así como el análisis cualitativo y comparativo.

Respecto a la metodología del análisis de impacto, se fundamenta en los análisis de Medina (2005) para la Comisión Económica para América Latina y el Caribe (CEPAL). Al respecto, la evaluación de impacto "tiene como propósito conocer si el programa produjo 
los efectos necesarios en los beneficiarios y analizar si los cambios observados en los beneficiarios, pueden asociarse a los efectos del programa" (Medina, 2005, p. 29). En otras palabras, la evaluación de impacto busca analizar si una política funciona o no. Medina aclara que "el impacto se mide sobre otra(s) variable(s) asociadas al nivel de vida de la población” (2005, p. 28). Acorde con este postulado, se tienen en cuenta los niveles de desigualdad, de pobreza y de educación de la población, tanto en Chile como en Colombia.

Ahora bien, desde el punto de vista científico, Medina (2005) puntualiza que el análisis de impacto se realiza respondiendo a las dos preguntas siguientes: ¿qué hubiera pasado si el programa no se hubiera realizado? y ¿cómo debería mejorarse el programa para maximizar sus beneficios en las variables de impacto? La presente reflexión incluye elementos de respuestas a estos cuestionamientos de rigor, con lo cual contamos con un marco de análisis de impacto lo suficiente como para alcanzar conclusiones relevantes en la materia.

Se plantea la hipótesis que las políticas de transparencia en Chile y Colombia, si bien constituyen iniciativas valiosas de prevención y lucha contra la corrupción, han tenido un impacto mitigado a nivel institucional, pero favorable a nivel cultural y político. El objetivo general del presente trabajo consiste en analizar, desde un enfoque comparado, el impacto de las políticas de transparencia en dos democracias regionales, con el objetivo de comprender cómo afecta la corrupción a la calidad de la democracia latinoamericana hoy en día. En este orden de ideas, se han planteado cuatro (4) objetivos específicos a continuación:

1. Analizar el impacto comparado de las políticas de transparencia en la calidad de la democracia de los casos seleccionados.

2. Mostrar como la corrupción política afecta la calidad de la democracia en Latinoamérica.

3. Evaluar como las políticas de transparencia en Chile y Colombia han contribuido a frenar o no esta afectación.

4. Evaluar el papel de la sociedad civil en el control social y la prevención de la corrupción.

\section{Marco conceptual}

Este análisis tiene orígenes antiguos, pues desde la democracia ateniense los líderes tenían responsabilidad política por sus decisiones. A lo largo de la historia de la democracia y en particular con el advenimiento del Estado liberal en el siglo XVIII, este principio se perdió. Renacen en este primer cuarto del siglo XXI las ideas de políticas anticorrupción, control social, transparencia activa y transparencia pasiva. 
Valdivieso, Bernas y Ganga citan la definición de Piotrowski del concepto de transparencia: "la apertura de las organizaciones del Estado" (Piotrowski, como citó Valdivieso et al., 2014, p. 51), la cual se concreta en "piezas de información de interés público ordenadas y dispuestas de forma tal que sean completas, claras y auditables fortalecerían la calidad de la gobernabilidad y del sistema democrático" (Valdivieso et al., 2014, p. 48). Por otro lado, la transparencia pasiva "dispone que toda persona tiene el derecho a solicitar y recibir información de cualquier órgano de la Administración del Estado, en la forma y condiciones que establece la Ley" (Valdivieso et al., 2014, p. 51).

Se analiza ahora el concepto de corrupción utilizado en las fuentes consultadas. Newman y Ángel (2017) acuden a la definición de Transparencia por Colombia, centrada en la violación de las normas y límites de las competencias que atañen al ejercicio del poder público, así como en la obtención de beneficios personales. Se trata de una definición que parte de una categoría jurídica, y por ende es desde arriba:

Transparencia por Colombia ha definido la corrupción como el abuso de poder o de confianza por parte de un actor para obtener beneficios personales o de un grupo determinado de poder, en detrimento de los intereses colectivos. (Corporación Transparencia por Colombia, 2015, p. 6)

Por el contrario, Valdivieso et al. acuden al enfoque desde abajo, con especial interés en la percepción de la corrupción. La percepción del fenómeno permite estudiar el fenómeno, ya que este existe porque la gente lo percibe de diversas maneras, de ahí la idea de encuestas de percepción de la corrupción:

Por otra parte, las mismas fuentes informan que la mayor parte de los individuos encuestados valoran el sistema democrático chileno, respetan sus instituciones, perciben que en el país hay consideración por sus derechos, y no tienen percepción de problemas de corrupción. (Valdivieso et al., 2014, p. 58)

Este contraste en el abordaje del concepto de corrupción no puede pasar desapercibido, ya que en Colombia se acostumbra abordar el tema desde lo punitivo y lo legal. Este es un enfoque que no deja de ser profundamente problemático, en términos de los límites que impone a la acción pública contra el flagelo de la corrupción, como lo es contar con un sinnúmero de normas que no son implementadas a cabalidad en la totalidad del territorio, o poner a disposición de los ciudadanos una serie de canales de acceso a información pública, que nadie consulta. Las encuestas de percepción en Colombia son tomadas como una consecuencia del delito, más no como insumos para un cierto cambio en la cultura política. Mientras en Colombia el enfoque es normativo, en Chile el enfoque es preventivo. En Chile, por su lado, existe un marco jurídico 
completo y coordinado, inclusive mejor que el de varios países latinoamericanos. Lo que significa que en Chile existe una cierta cultura de la probidad y en particular, siguiendo a los autores, existe confianza entre el Estado y la sociedad civil:

En las relaciones entre "confianza" y la percepción de "corrupción" en el gobierno, por una parte, y las puntuaciones de transparencia municipal, por otra, observamos relaciones positivas, la confianza en el gobierno municipal y la percepción de corrupción incrementan la puntuación de transparencia. (Valdivieso et al., 2014, p. 60)

En cambio, en Colombia los episodios recientes ${ }^{15}$ demuestran que esta confianza se rompió. Ahora bien - a partir de este enfoque - se ha desarrollado una experticia técnica basada en el derecho penal, como se definió, que ha dominado las políticas públicas de la corrupción, en detrimento de un abordaje preventivo desde abajo, centrado en el cambio cultural. Por otro lado, existe una tendencia mundial a abordar la corrupción desde el sector de los negocios, la cual insiste más en la regulación del comportamiento individual, a partir de la ética y de ciertas herramientas igualmente técnicas. La juridicialización de la lucha contra la corrupción, aunado al auge de los negocios en un mundo globalizado, favorece el incremento de que se trate de manera técnica. La tecnocracia creciente alrededor de un problema político y socio-cultural -que además es altamente complejo por la cantidad de variables que inciden en el mismo- conlleva a su simplificación y por ende, el cambio socio-político se pierde de vista ${ }^{16}$. Nuestra postura en el siguiente debate, es que la corrupción es un objeto de estudio de la ciencia política, de la sociología, así como de la disciplina de relaciones internacionales.

Se mencionan a continuación los aportes de la ciencia política a la investigación sobre el fenómeno de la corrupción. En particular, sobresalen los aportes del politólogo neerlandés Gjalt De Graaf en cuanto a una teoría contextual de la corrupción, basada en el enfoque cultural y organizacional: "las condiciones culturales y estructuras organizacionales

15. Se hace referencia a los resultados del Plebiscito sobre los Acuerdos de Paz de Colombia de 2016, que dieron una mayoría de "No" con un 50.21 \%. Se observa la falta de confianza, la polarización, así como la incapacidad de la sociedad colombiana para alcanzar consensos democráticos.

16. Altos niveles de experticia, siguiendo a Dahl, son perjudiciales para la democracia: Dahl rechaza lo que él mismo llama los guardianships o formas democráticas basadas en la creencia que algunos son mejores que otros para gobernar a favor del bienestar general. El equivalente en español, sería las tecnocracias. El argumento mayor es que esto va en contra del principio democrático fundador que es la igualdad de oportunidades para gobernar. Finalmente, los tecnócratas también logran capturar el poder en las democracias contemporáneas. Dahl nuevamente afirma que el criterio tecnocrático no es político, sino que es objetivo, y que: "sus implicaciones para la democracia dependen del juicio que se haga de la idoneidad del hombre común” (Dahl, 1994). 
en las cuales es más probable que ocurra la corrupción" (De Graaf y Huberts, 2008, p. 640). La teoría contextual inválida el enfoque juridicista de la corrupción, por cuanto no se necesitarían más normas para combatirla y adaptarse a las evoluciones del crimen, sino inducir un cambio político y cultural preventivo en la sociedad.

Se revisa la definición que aportan De Graaf y Huberts sobre la corrupción, la cual insiste - en primera medida - en que no se trata de una acción puramente individual, punto sobre el cual en cambio se basa el enfoque legalista de la anticorrupción ${ }^{17}$, sino que necesariamente incluye una tercera parte, un ofertante, dicho de otra manera: alguien que presenta la necesidad de obtener un beneficio personal en detrimento de las normas vigentes, así como del interés público. En segunda medida, De Graaf y Hubert insisten en la recompensa que es el resultado de la influencia ejercida sobre el servidor público:

Public officials are corrupt when they act (or fail to act) as a result of receiving personal rewards from interested outside parties (Huberts and Nelen 2005) [...] An important element of the definition is that, in this article, corruption always includes an interested third party [...] Also important is the element of "personal rewards," which include non monetary rewards, and the consideration that, as a result of these personal rewards, an act (or failure to act) of a public official is influenced. (De Graaf y Huberts, 2008, p. 641)

Por último, se van a repasar las tipologías de la corrupción que identifican estos autores: la corrupción individual basada en las motivaciones personales, en la trayectoria del corrupto, en las características psicológicas y los riesgos personales que son asumidos con la corrupción ${ }^{18}$. La corrupción organizacional que se concentra en la falta de supervisión, así como en la estructura y la cultura organizacionales -ejemplo: Odebrecht- ; y el intercambio de favores público-privados enfocado en las relaciones pasadas y las redes de corrupción ${ }^{19}$. Estas tipologías se adaptan mejor a las últimas evoluciones del fenómeno y permiten comprenderlo mejor que la tradicional distinción corrupción pública/corrupción privada, hoy en día obsoleta.

17. La lucha contra la corrupción legalista se limita a buscar y encontrar a un culpable necesario, que sea condenado por los hechos. Es limitada porque no entiende que el fenómeno político y socio-cultural pone en esa posición a cualquier persona, ya que existe una demanda, una necesidad de obtener beneficios personales, que siempre será dirigida al Estado y sus representantes.

18. Un ejemplo de este tipo de corrupción es el empresario colombiano de Hyundai Carlos Mattos. Para mayor información, consultar: Segunda orden de captura contra Carlos Mattos (2019).

19. Un ejemplo de este tipo de corrupción es el de Jair Bolsonaro y Sergio Moro. Para mayor información, puede consultar el artículo del Clarín (La corrupción en Brasil. Internas en Brasil: Jair Bolsonaro designa procurador general a un duro crítico del juez del Lava Jato, 2019). 
Merat y Roth (2006) aportan una definición de la sociedad civil, dado el papel que cumple en la mitigación de la corrupción. Según los autores, se entiende por sociedad civil aquellas asociaciones sin ánimo de lucro que son independientes del Estado, así estén o no constituidas legalmente, y que buscan la producción, obtención o defensa de los servicios públicos ${ }^{20}$. Ahora bien, éstos resaltan que los actores de la sociedad civil pueden cambiar dependiendo del papel que ejercen en la política. Por ejemplo, los gremios empresariales pueden ser parte de ésta, siempre y cuando estén ejerciendo un papel de influencia en búsqueda de un bien común. En cambio, si el gremio está ejerciendo presión para obtener contratos y otras actividades que le representan un beneficio privado, dejará de considerarse como parte de la sociedad civil.

Por último, los autores mencionan que las ONG no son, de facto, parte de la sociedad civil. Aunque se puede considerar que estas organizaciones velan por la defensa, producción y obtención de bienes y servicios públicos, es importante tener en cuenta que, en muchas ocasiones, este tipo de organizaciones pueden comportarse como empresas que buscan una ganancia privada. Esto como consecuencia de la influencia que tienen las donaciones de la cooperación internacional en el ámbito político interno (Merat y Roth, 2006).

Por consiguiente, la sociedad civil puede influenciar los incentivos dirigidos al sector público, así como informar a los ciudadanos sobre las herramientas para reclamar mayor transparencia en la administración pública.

Para finalizar, los aportes de la disciplina de las relaciones internacionales se presentan desde tres ejes fundamentales:

1. Los límites del control socio-político de las finanzas globales, que escapan hoy a cualquier regulación macroeconómica sustancial, capturan los recursos de los países en vías de desarrollo, impiden la industrialización y el desarrollo, profundizando al tiempo las desigualdades globales ${ }^{21}$.

2. La ética se presenta hoy en día como una necesidad global. Rainelli (2010) hace un llamado a reanudar la ética y la economía, abandonando la fiebre por la eficiencia de los mercados y las ganancias excesivas a corto plazo que derivan en un capitalismo salvaje.

3. La rendición de cuentas, dentro del marco de la OCDE, se presenta hoy en día como un instrumento internacional contra la corrupción ${ }^{22}$.

20. Así lo definen Merat y Roth (2006). La efectividad de las instituciones en la lucha contra la corrupción: la estrategia de los Pactos de Transparencia en Colombia.

21. Así lo muestran, entre otros, Fajnzylber (1990).

22. Así lo muestran los trabajos de Rodríguez y Sarthou (2008). 


\section{Impacto comparado de las políticas y programas de transparencia en Chile y Colombia}

\section{La caracterización de la corrupción en Chile y Colombia}

En Colombia, las cifras se concentran en cuatro delitos de tipo penal que son el cohecho, la omisión, el peculado por apropiación y la concusión. Newman y Ángel, sostienen que:

[...] entre los delitos que se relacionan con formas de corrupción, los más sancionados [...] corresponden a las formas de corrupción de soborno (por el delito de cohecho por dar u ofrecer), apropiación de bienes públicos y bienes de uso privado (por los delitos de omisión del agente retenedor o recaudador y peculado por apropiación) y extorsión (por el delito de concusión). (2017, pp. 18-19)

Estos cuatro delitos representan el $75 \%$ de los delitos penales relacionados con corrupción en Colombia entre el 2009 y el 2016. Las formas de corrupción correspondientes identificadas son el soborno, la apropiación de bienes públicos y privados, así como la extorsión.

Ahora bien, resulta interesante rescatar que -de lado de las faltas disciplinarias por corrupción a los alcaldes de Colombia- el 75 \% tienen que ver con apropiación de bienes públicos y privados y nepotismo. Así las cosas, el soborno, la apropiación de bienes, la extorsión y el nepotismo constituyen las principales características de la corrupción en Colombia.

En cuanto a Chile, se encuentra que el Delito de Mayor Connotación Social (DMCS) asociado con corrupción es definitivamente el delito contra la propiedad, esto dentro de un contexto de incremento sustancial de la población carcelaria debido, entre otros, a la entrada en vigor en el año 2000 del nuevo Código Procesal Penal (Salinero, 2012). Sin embargo, resulta interesante observar que:

Mientras a fines de la década pasada el promedio de delitos contra la propiedad sin apoderamiento violento era de un $24.3 \%$, en los últimos cinco años de medición de este estudio ha reflejado una pequeña reducción, siendo del orden del 23.8\%. (Salinero, 2012)

Estos resultados confirman que en Chile los delitos asociados con corrupción son menos representativos que en Colombia, y además no son tan diversos, sino que se concentran en un solo tipo penal que es el apoderamiento. En Colombia, como se observa son cuatro tipos penales. No solamente esto, sino que el apoderamiento apenas representa un cuarto de los delitos penales, cuando en Colombia estas cifras - guardadas las 
justas proporciones $-{ }^{23}$ sobrepasan el $60 \%$ de los delitos penales cometidos. Por último, estos delitos vienen en disminución en nuestro vecino chileno, información que no se confirma para Colombia.

Como lo anota la Fiscalía de ese país (Fiscalía de Chile, s.f.), allá también se persiguen los otros delitos penales como el tráfico de influencias: alcanzando un índice de calidad de la regulación en la materia del 7.4\%. Colombia llega al $4.6 \%$ y no cuenta actualmente con regulación de conflicto de interés. Vale la pena anotar que en Chile, estos delitos representan porcentajes inferiores al $25 \%$ de los delitos cometidos en total.

Del lado del análisis comparativo de los índices de percepción de la corrupción en 2018, un primer contraste salta a la vista: mientras en Chile tan solo se percibe un 33 \% de corrupción; en Colombia esta misma cifra alcanza casi el doble con un $64 \%$. Recordemos que el promedio en Latinoamérica es bastante alto, con el $63 \%$; mientras que en los países de la OCDE la percepción baja al $32 \%$. Esto significa que mientras que Chile se aproxima a la media de los países de la OCDE, Colombia sigue estancada en la percepción de la corrupción promedio latinoamericana que es mucho más alta. Algunas explicaciones para el incremento del $63 \%$ de la percepción latinoamericana probablemente estén relacionadas con la instrumentalización política de la corrupción -junto con la judicialización de la política- que operó la derecha sobre la izquierda en Ecuador, Brasil y Argentina principalmente. Pero también confirma que Colombia se encuentra en una situación de atraso importante en relación a Chile en esta materia, lo cual en últimas significa que el Estado colombiano no ha logrado obtener la confianza de la población.

No obstante lo anterior, en los dos países se permiten las contribuciones en efectivo durante las campañas electorales, lo que impacta en que alrededor de un $83 \%$ de los chilenos y de los colombianos piensan que sus gobiernos actúan en favor de grupos poderosos. Exceden, en este sentido, el promedio del 75 \% de latinoamericanos que opinan lo mismo, encontrándose muy sobre la media latinoamericana. No solamente esto, sino que el contraste se puede invertir por cuanto en Chile 68 \% de la población

23. Se hace la salvedad que, en las cifras chilenas no se detalla la proporción de delitos asociados por corrupción dentro de aquellos por apoderamiento sin violencia. Aunado a lo anterior, las cifras colombianas tienen una base diferente, por cuanto corresponden a la cantidad de casos con al menos una condena (Newman y Ángel, 2017, p. 18). Mientras que la base de las estadísticas chilenas consultadas es la población carcelaria, o sea condenada a la cárcel. La base chilena representa un obstáculo para el análisis del caso colombiano, porque la legislación es diferente, y en Colombia existe la condena de "casa por cárcel", que en Chile se da únicamente para penas cortas, y en el tipo de "remisión condicional" y "reclusión nocturna" (Ley 18216, 1983). En Colombia, actualmente cursa en el Congreso un proyecto de ley que elimina la casa por cárcel a los corruptos. 
- a pesar de encontrarse en una situación más avanzada de percepción de la corrupción que Colombia - considera que su gobierno está actuando mal en la lucha contra la corrupción; y en Colombia esta misma cifra es tan solo del 59 \%. Esto explicaría que probablemente en Chile existe mayor control social que en Colombia, lo cual al final tiene un impacto en el contraste en cuanto a la percepción.

Por último, desde el punto de vista institucional y de garantías ofrecidas por el Estado a esta lucha, vale la pena mencionar que en los dos países el líder de la entidad coordinadora anticorrupción cambia al alternar el gobierno. Así mismo, en los dos países sigue siendo una posición eminentemente política con algunos criterios formales de selección, hechos que impactan sobre el más del 80 \% de opinión negativa alrededor del tráfico de influencias en estas democracias modernas.

\section{Impacto comparado de las políticas y programas de transparencia}

Valdivieso et al. (2014, p. 47) reportan que, "en las últimas décadas, la transparencia ha pasado a ser un tema de gran actualidad en América Latina, en la esfera de las políticas públicas". Se trata de un paradigma de la política pública anticorrupción, el cual se basa en que: "la transparencia, las organizaciones internacionales han apoyado decididamente los esfuerzos de los gobiernos de la región en la lucha contra la corrupción y en el desarrollo de políticas de transparencia (De Shazo, 2007, citado en Valdivieso et al., 2014, p. 47).

\footnotetext{
En el ordenamiento jurídico colombiano [...] se encontró una gran cantidad de normas jurídicas para [promover la rendición de cuentas]. Así, existen normas en materia de: i) transparencia y acceso a la información pública; ii) producción de información sobre corrupción; iii) procesos de planeación y gestión; iv) control interno; v) control social; vi) promoción de la integridad y la legalidad; y vii) lucha contra la impunidad. (Newman y Ángel, 2017, p. 24)
}

Este marco normativo ha buscado incrementar la probabilidad de detección de la corrupción. No obstante, las autoras adelantan que "la eficacia de estas normas e instituciones se ha encontrado con varios obstáculos de implementación y coordinación" (Newman y Ángel, 2017, p. 24).

Los departamentos periféricos (Guainía, Vaupés, Vichada, Caquetá, Putumayo, Chocó y Guajira) demandan mayores esfuerzos en el acompañamiento técnico que deben aportar las entidades del orden nacional que lideran la política pública anticorrupción. (Newman y Ángel, 2017, p. 25)

Las leyes son iguales para todo el mundo, pero aquí se necesita un enfoque diferenciado multisectorial según el mapa de riesgo de corrupción en cada uno de estos departamentos periféricos, que corresponden a los mismos que se encuentran 
en una profunda desigualdad respecto a la satisfacción de las necesidades jurídicas ${ }^{24}$. Igualmente, se hace imperativo tener en cuenta el Mapa de Riesgo de Corrupción para el Posconflicto.

Desde el punto de vista institucional, las autoras plantean la necesaria reforma del Consejo Nacional Electoral y de la Comisión Nacional del Servicio Civil, así como de las contralorías territoriales: instituciones que fueron identificadas con alto riesgo de corrupción en Colombia, por ser el fortín de políticos locales. Además, Newman y Ángel insisten en los déficits de coordinación de competencias, recolección y transferencia de información entre la Procuraduría, la Contraloría y la Fiscalía General de la Nación. Finalmente, "los niveles de rendición de cuentas y sanción efectiva continúan siendo muy bajos" (Newman y Ángel, 2017, p. 27), por lo que se requiere retomarlos al alza.

En Chile, se insiste en el marco institucional de la prevención y como este impacta en la percepción de la corrupción. Por lo tanto, el problema se aborda desde una perspectiva diferente en relación a la corrupción público-privada. Valdivieso et al. (2014, p. 51) afirman que la política de transparencia ha tenido dificultades de implementación en los gobiernos locales - municipios- en Chile. En Colombia, en cambio, el narcotráfico es uno de los factores principales de la corrupción.

Los autores son reticentes en afirmar que estas políticas realmente han detenido la corrupción. De un lado, existe todo un sustento teórico crítico que insiste sobre el hecho que la disposición de piezas de información "no tiene efectos mecánicos en la sociedad" (Friedrichs y Schmidt, 2002, citado en Valdivieso et al., 2014, p. 48). En realidad, el acceso a la información depende de las características de la desigualdad de la población y del fenómeno de corrupción que experimenta dicha población. Con una desigualdad alta, el acceso a las piezas de información estará desigualmente repartido; y en este caso, las piezas de información van incluso a profundizar aún más las desigualdades de acceso a la información. De otro lado, los autores reportan que incluso ni la comunicación, ni la confianza, ni la participación ciudadana aumentan de forma automática con la mera disposición de piezas de información ya que estas no constituyen un canal para influir sobre la agenda pública. En términos de cultura política, estos son "espacios inducidos" que -por sí mismos- no tienen una incidencia significativa sobre el activismo político (Valdivieso et al., 2014, p. 48). Por ende, su impacto sobre la democracia es nulo o limitado desde el punto de vista politológico. Inclusive, los autores reportan que estas piezas "proveen poca transparencia de facto, por los formatos y porque hay numerosas circunstancias adicionales

24. Para un cuadro comparativo del mapa político de Chile y Colombia, se puede consultar: Tabla 2.3 (OCDE, 2019, p. 38). 
que impiden a las personas procesarlas y actualizarlas en relación con sus intereses y problemas concretos" (Etzioni, 2010, citado por Valdivieso et al., 2014, p. 49). Los autores concluyen que se requieren estrategias de implementación en contextos diferenciados.

En este orden de ideas, estas políticas no produjeron los efectos necesarios en los beneficiarios, porque fueron medidas básicamente muy limitadas para trascender la complejidad del problema de la desigualdad del acceso a la información, así como de la participación ciudadana y la confianza, como herramientas de prevención y control social de la corrupción. Estas políticas no funcionaron como se esperaba y no tuvieron el impacto esperado en los beneficiarios. Valdivieso et al., explican que la implementación de la Ley de Transparencia chilena no pasó del 30 \% en los sitios web municipales (2014, p. 51). Los autores insisten en la falta de un enfoque contextual o de "facilitación" (Valdivieso et al., 2014, p. 52) para la implementación de la Ley en los municipios chilenos, el mismo problema que aqueja a Colombia: "para ciudadanos con bajos niveles relativos de educación, los costos son altos, dado que el tiempo que necesitan para poder interactuar con la información en esos formatos es mayor" (Valdivieso et al.,2014, p. 53). El lenguaje técnico es el mayor impedimento al acceso a la información, que ha sido formateada por abogados y técnicos. A diferencia, en Colombia existe una preocupación por transmitir en lenguaje ciudadano, pero el denominado lenguaje ciudadano, que ocasionalmente cae en el culturalismo, también alimenta en doble vía la ignorancia de la población, con simplificaciones extremas. Se requieren ciudadanos educados para comprender las piezas de información dispuestas virtualmente.

De igual forma, Gamarra (2006) afirma que una de las causas de la corrupción no es determinada por la indiferencia de la ciudadanía a una buena administración pública, sino "porque no tienen los medios para mantener al gobierno disciplinado y apegado a las leyes" (p. 22). La investigación estableció que la existencia de una maquinaria política local fuerte es un factor común en los departamentos más corruptos del país. Esta pudo establecerse como consecuencia de un vacío de poder del Estado que permitió la cooptación de maquinarias políticas locales. Por consiguiente, en aquellas regiones donde éstas mantienen un poder dominante, es donde más ocurre corrupción, dado que los recursos del Estado, en su mayoría transferencias estatales, son presas de grupos de interés afines a las maquinarias. Esto a su vez, hace que la rendición de cuentas de estas maquinarias sea mínima, ante el desconocimiento de los ciudadanos sobre los mecanismos apropiados para exigirle a los mandatarios locales.

De esta manera, el papel de la sociedad civil resulta fundamental para que disminuya la corrupción, dado que este actor puede ser un medio entre la ciudadanía y el Estado para exigir una administración efectiva, garantizar el buen uso de las transferencias, y modificar 
los incentivos. La sociedad civil puede modificar los incentivos de la administración pública, resaltando a aquellos funcionarios que han manejado de manera adecuada los recursos públicos, aumentándoles su reputación. De esta manera, como afirman Merat y Roth (2006), las "alianzas entre actores de la sociedad civil y funcionarios virtuosos del poder podrían empezar a transformar de manera positiva la relación Estado-comunidad” (p. 6).

Por ende, se confirma la hipótesis según la cual las políticas de transparencia han tenido un impacto mitigado a nivel institucional.

Ahora bien, ¿qué hubiera pasado si el programa no se hubiera realizado? Estas iniciativas si bien cuentan con numerosas falencias en su implementación e impacto mitigado, en realidad no resulta tampoco deseable no haberlas realizado porque abren el camino y lanzan una iniciativa que indica una nueva socialización respecto de lo público. Si no se hubieran realizado, las instituciones municipales en Chile no se habrían enfrentado al desafío de implementarlas; o no se habrían identificado los déficits de coordinación de competencias, recolección y transferencia de información. Por el lado ciudadano, éstos no se habrían confrontado nunca a nuevos espacios de socialización que implican manejo informático y un conocimiento básico de ciertos tecnicismos. De alguna u otra manera, estas políticas inducen el acercamiento y la modernidad del Estado, pero siguen siendo profundamente insuficientes.

¿Cómo debería mejorarse el programa para maximizar sus beneficios en las variables de impacto? Siguiendo a Medina, estos programas requieren un enfoque diferenciado y desde abajo, en términos de percepción de la corrupción. En Colombia, por ejemplo, se insiste mucho en disminuir la discrecionalidad de los funcionarios públicos, reducir las rentas monopólicas, incrementar la rendición de cuentas, así como las posibilidades de detección gracias a sistemas de intercambio de información de tipo público-privada, contractual y relativa a los beneficiarios reales de la corrupción. Respecto a este último punto, Colombia ha realizado esfuerzos importantes para agilizar estos sistemas.

Por el lado chileno, los autores realizaron una encuesta de percepción a los funcionarios públicos municipales y dedujeron que: "una política que considere programas formativos para los ciudadanos sobre cómo usar los instrumentos disponibles para la transparencia sería una buena estrategia para fortalecer la política" (Valdivieso et al., 2014, p. 57). En palabras de Robert Alan Dahl, Chile requiere incrementar su capacitación social sobre la norma, con el fin de sobrepasar las profundas diferencias que se dejan entrever en la encuesta y alcanzar un consenso sobre los beneficios de la Ley de Transparencia promulgada en el gobierno de Bachelet. Otros elementos de mejora identificados por los autores son la comunicación organizacional y revisar "los procedimientos para asignar las tareas de la transparencia y la racionalización de los procesos” (Valdivieso et al., 2014, p. 58). 


\section{Impacto de la corrupción en los procesos democráticos chileno y colombiano}

Newman y Ángel (2017) se detienen en varios elementos del contexto sociopolítico-cultural, así como en varios elementos del marco institucional colombiano que favorecen la corrupción.

El primer elemento sociopolítico-cultural es el clientelismo. En otras palabras, el intercambio de "favores" que necesariamente implican dinero de carácter público a cambio de votos. Por la intermediación de dineros públicos, se le llama un clientelismo de mercado. Funciona gracias a la visión parroquial de los miembros del Congreso ${ }^{25}$, quienes se encuentran directamente conectados con intermediarios políticos en las regiones. Estos intermediarios locales usualmente también se mueven en otras esferas y hacen parte de estructurales criminales, o derivan de estas ${ }^{26}$; por lo que el ejercicio pleno de la democracia se encuentra capturado en Colombia. Esta es una asociación profundamente perversa para el país, indestructible hasta el momento.

Sin embargo, tanto el fraccionamiento de las ideologías así como la tendencia de los partidos políticos a volverse empresas electorales -y el impacto de esta tendencia en los sistemas de partidos que nos evoca Juan Carlos Monedero (2019) - han indirectamente favorecido el incremento de la cantidad de partidos así como una explosión de partidos de tercera vía o alternativos. Pero, estos partidos se esconden políticamente bajo este estigma, cuando en realidad pertenecen a las mismas dinámicas aquí enunciadas de los partidos tradicionales y lo hacen para capturar también esos votos de tercera vía. Los que son partidos auténticos de tercera vía, tienen dificultades para ganar las elecciones, están representados en los distintos espacios políticos garantizando el pluralismo, un valor democrático fundamental, pero siguen siendo minoritarios. Así las cosas, se perpetúan en el poder los partidos tradicionales y esa lógica entre favores económicos a cambio de votos, encierra las dinámicas del desarrollo en un imposible.

Se observa, en la reflexión de Fajnzylber (1990), que el desarrollo como motor de una sociedad se basa en un círculo virtuoso entre el crecimiento y la competitividad. Dicho de otra manera, la lógica entre favores económicos a cambio de votos afecta la generación de ahorro interno para las regiones y por lo tanto impide su canalización hacia aquellos sectores prioritarios de la industria nacional, que son creadores de empleo, impulsan la productividad y fundamentan la competitividad. Por lo tanto, si

25. Se trata de defender los intereses locales, particulares, egoístas en el espacio de decisión nacional, en detrimento del interés público.

26. En particular, el narcotráfico "requiere de ciertas inmunidades [políticas] para poder subsistir" (Newman y Ángel, 2017, p. 21). 
no impiden, atrasan generaciones enteras el desarrollo. Según el Informe Nacional de Competitividad 2018-2019 (s.f.) del Consejo Privado de Competitividad, Colombia está estancada en productividad y apenas alcanza el puesto 58 en los rankings internacionales de competitividad. En todos los rankings, la competitividad se encuentra en caída libre.

Ahora bien, la sociedad civil puede re direccionar incentivos e informar a la ciudadanía sobre sus derechos y canales que les permitan exigir una administración pública adecuada. Un ejemplo es la implementación de los pactos de transparencia en Tumaco, Nariño, entre el 2004-2005. A principios del 2004, explotó un escándalo de corrupción por la pérdida de 7.800 millones de pesos del régimen subsidiado de salud, casi la mitad del presupuesto anual del municipio destinado a cubrir la salud básica de más de 100.000 personas de los estratos más bajos.

Ante esta situación, la Contraloría General realizó un informe sobre la contratación durante el período entre el 2002-2003. Se encontraron contratos mal ejecutados en construcción de carreteras, descontaminación de ríos, construcción y mejoramiento de acueductos, redistribución de materiales escolares, etc. En particular, contratos que buscaban prevenir y tratar la malaria habían sido desviados de forma masiva; así como no existía un informe sobre las regalías recibidas por el municipio entre el 2002-2003, ni de la ejecución del presupuesto municipal -que superaba los 40 mil millones de pesos para una población de 150.000 habitantes (Merat y Roth, 2006).

Por consiguiente, la sociedad civil liderada por la Pastoral Social, decidió buscar el apoyo de varias organizaciones nacionales e internacionales, al igual que del Programa Presidencial de la Lucha Contra la Corrupción. La suscripción al pacto se dio en agosto de 2004. En un año, el Comité de seguimiento del pacto envió numerosas solicitudes de información a diferentes instituciones nacionales y departamentales (Merat y Roth, 2006).

El comité recibió informes de transferencias, listas de beneficiarios de subsidios, al igual que reportes sobre el proceso de contratación del acueducto. Resulta interesante observar que se adelantó un programa radial en el cual los funcionarios debían rendir cuentas y aportar información sobre su gestión. Así mismo, se organizaron múltiples talleres de formación que tenían como objetivo capacitar a los miembros del Comité de seguimiento del pacto en veedurías ciudadanas y marco legal de regalías. El alcalde se hizo presente para responder las solicitudes ciudadanas; y empezó a existir información mensual sobre las transferencias del sistema general de regalías. También se estableció, acorde con la normativa, una oficina de archivo para recuperar información perdida. Además, se organizó una oficina de quejas y reclamos, y el comité pudo establecer un canal de comunicación más directo con los secretarios del despacho, para que los ciudadanos pudieran estar más informados sobre los programas y actividades de la 
administración pública. Esto a su vez evitó desvíos masivos, los salarios y los contratistas públicos fueron pagados a tiempo y en su totalidad, así como el gobierno nacional aumentó su compromiso con Tumaco (Merat y Roth, 2006).

Como se observa en Tumaco, la democracia puede subsistir inclusive con altos niveles de corrupción. Pero, resulta un nivel de dificultad superior pensar en una democracia sin integridad ni justicia social, por ende sin desarrollo. Por otro lado, la corrupción profundiza y agrava la desigualdad nacional. Se puede, incluso, establecer que: "las gobernaciones con peores resultados en el Índice de Gobierno Abierto y el Índice de Transparencia de las Entidades Públicas, son aquellas ubicadas en zonas de periferia y con menores capacidades estatales" (Consejo Privado de Competitividad, s.f.), en particular la Orinoquía y la Amazonía, regiones que concentran ocho departamentos de Colombia -Arauca, Casanare, Vichada, Guainía, Guaviare, Vaupés, Amazonas y Putumayo-. Esto crea una verdadera fractura que divide al país en cuanto a la satisfacción de las necesidades jurídicas. Resulta interesante observar que estos departamentos no aparecen como los más afectados por el conflicto armado en Colombia (Duarte, 2018) y además son aquellos con la menor cantidad de desaparecidos forzados en el país (Ortiz, 2019). Lo anterior permite inducir que, en Colombia, dónde no hubo conflicto armado, hubo corrupción.

En resonancia con los datos de la OCDE respecto a las contribuciones en efectivo permitidas en Colombia durante las campañas electorales, el Informe (2017) agrega que el $13 \%$ de los empresarios que realizan estas contribuciones esperan recibir beneficios a cambio. Dicho de otra manera, la corrupción también crea un círculo perverso entre los favores políticos y el dinero proveniente del sector privado. Atada de pies y manos por la corrupción, la democracia se encuentra exhausta en este país.

También atañe a la democracia una reflexión sobre sus valores, en contraste con los valores sociales. Newman y Ángel (2017, citando a García Villegas, 2009), subrayan que en Colombia triunfa una cultura del incumplimiento de las reglas -también llamada la cultura del desacato-basada en una "concepción flexible y negociable de la ley" (p. 21). En particular, también se caracteriza una cultura mafiosa, la cual "tiene un orden basado en la figura del patrón local y un sistema informal de justicia” (Newman y Ángel, 2017, p. 21). Nada más contrario a los valores democráticos, que según Dahl (1994) son la justicia y el respeto como bases de la igualdad. La figura del patrón es el contrario de la virtud aristotélica. Esta cultura tiene un impacto considerable en la democracia, porque afecta la autoridad y captura el poder que emana del pueblo. Al respecto, Monedero señala un "vaciamiento democrático" (Monedero citado en Lynch, 2017, p. 44). Las instancias de control, incluso las entidades anticorrupción -como lo muestra 
la OCDE- y ahora la justicia, se encuentran altamente y peligrosamente politizadas en la democracia colombiana. No sorprende -en estas condiciones- que actores políticos "mediocres" se hayan tomado el poder en Colombia (Rojas, 2019).

Del lado chileno, en la sociedad en cambio sí hubo reconciliación. No obstante, el mismo Carlos Ominami (2018) reconoce que la Concertación también tiene una cara oscura, con un éxito mitigado respecto a la lucha contra la desigualdad. Aclara que Chile escapa a la tendencia actual en el subcontinente latinoamericano, de una preocupante recuperación de la pobreza. Sin embargo, sí existe un incremento de la riqueza de los más ricos, producto del crecimiento económico. Por ende, la riqueza no se reparte: esto supone un sistema fiscal deficiente. El desempleo juvenil, la jubilación como factor de empobrecimiento, un sistema de comunicaciones concentrado, y la reproducción social del sistema educativo son problemas heredados de una falta de capacidad del Estado.

En Chile se presenta, en consecuencia, una democracia "de baja intensidad" con un déficit de pluralismo democrático alto. En contraste, el país cuenta con un presidencialismo fuerte. Chile comparte esta forma de gobierno con Colombia, la cual no está exenta de problemas ${ }^{27}$, pero en Chile el congreso está totalmente subordinado a las facultades presidenciales, lo cual no es el caso en Colombia. Respecto a la corrupción, Ominami (2018) reconoce que esta se expande en múltiples sectores, de hecho el Informe de Integridad de la OCDE menciona el "Pentagate" en Chile en 2015 (OCDE, 2019 p. 78) como uno de los mayores escándalos de corrupción en la región ${ }^{28}$, aunado al de Odebrecht que también tocó a Colombia. Por ende, se deduce que la corrupción impacta la calidad de la democracia, afectando el prestigio democrático en la ciudadanía y disminuyéndola, incluso sometiéndola a la decadencia. Estas falencias fraguaron el camino de Piñera, en la medida que se dividió la Concertación. Tanto en Chile como en Colombia la corrupción impactó a los gobiernos progresistas de forma considerable.

Ahora bien, "Sebastián Piñera, no busca corregir ni el modelo socioeconómico neoliberal ni el modelo político de democracia incompleta, sino profundizar ambos" (Garretón, 2012). Sin embargo, como lo afirma Ominami (2018), Piñera - en virtud de una cierta trayectoria - no es un hombre de la dictadura, lo que le permitió ganarse a sectores de centro-izquierda que rechazan los partidos tradicionales. Como en otras partes del mundo, la derecha logra capitalizar el descontento general. En este orden de ideas, durante su primer mandato, como lo afirma Garretón: "la obligación de negociar con la oposición, lo [forzaron] a promulgar leyes que no correspondían a su

27. Puede derivar hacia un presidencialismo autoritario, como en Venezuela.

28. Para mayor información consultar: De los Reyes (2015). 
propia agenda sino a la de la oposición política y social y que podrían ser calificadas de progresistas" (2012, p. 11). La reforma tributaria de 1990 es el mejor ejemplo de estas concertaciones: "para asegurar la estabilidad de la democracia, la consolidación de la economía de mercado y la reconciliación social en el amplio sentido de la palabra nos pareció fundamental que el país hiciera un esfuerzo extraordinario" (Garretón, 2012, p. 105); que de hecho, alejaron a Piñera de los sectores más recalcitrantes de la derecha, opacando su primer mandato, a la sorpresa de los miembros de la Concertación. "La experiencia chilena muestra, en todo caso, los problemas de los progresismos a escala global, en un contexto latinoamericano incierto y marcado por reemergencias conservadoras" (Ominami, 2018, p. 4).

Se observan ahora las condiciones del marco institucional que favorecen la corrupción en Colombia según Newman y Ángel (2017). Las autoras analizan la existencia de monopolios de rentas económicas contrarios a la adjudicación competitiva, en "la contratación estatal, el acceso al empleo público, la asignación de permisos y licencias para dedicarse a actividades económicas lucrativas, la formulación de normatividad (Congreso), y los procesos electorales" (2017, p. 22). Los monopolios de rentas económicas se valen de "mecanismos legales e ilegales" (2017, p. 23) para favorecer el interés particular, en detrimento del interés general de la sociedad. "Por su parte, el lobby, la captura y la reconfiguración cooptada del Estado son los mecanismos más comunes para burlar los límites legalmente establecidos en materia de formulación de normatividad" (Newman y Ángel, 2017, p. 24).

Acorde con este análisis, la primera recomendación de la OCDE en cuestión de integridad (OCDE, 2018a, p. 3) apunta a mitigar el riesgo de captura de las políticas. Sobresale el punto en el cual se enfatiza la necesidad de "evaluar las funciones y recursos de los órganos de gestión electoral para garantizar su independencia y eficacia de facto" (OCDE, 2018a, p. 3) 29. Precisamente Newman y Ángel (2017) insistieron en la necesaria reforma del Consejo Nacional Electoral en Colombia, centrada en su independencia, lo cual tendría sin lugar a dudas un impacto positivo en la democracia colombiana, previniendo su captura. Igualmente, se hace urgente una regulación del lobby, pero desde abajo, desde las prácticas de los cabildantes.

El impacto también es en términos legales, pues a cada nueva ola de corrupción, el Estado responde con nuevas leyes. En Colombia, por ejemplo, contamos con una serie de Proyectos de Ley (PL) en trámite que derivaron de la consulta anticorrupción de

29. Cursivas tomadas del texto original. 
$2018^{30}$. Sin embargo, la dificultad que encuentran en el Congreso para subsistir, o para continuar con el proceso legislativo, señalan una acérrima voluntad de los congresistas de proteger y defender el sistema de intercambio de favores que los llevan y los mantienen en el poder. Por ejemplo, respecto al PL que busca garantizar el cumplimiento de los principios de transparencia, participación y control social, mediante la publicación de las declaraciones de bienes, renta y el registro de los conflictos de interés de altos servidores públicos, Colombia presenta un índice de robustez del sistema de declaraciones patrimoniales de apenas $53 \%$, es decir la mitad de las metas. Chile en cambio presenta un índice más robusto, con $77 \%$ de declaraciones patrimoniales y de intereses de funcionarios publicadas. Al respecto, la OCDE recomienda en segunda medida "mejorar la eficiencia, la eficacia y la apertura de la administración pública” (2018a, p. 4), también en su implementación regional diferenciada, con capacitación social sobre la norma y educación.

En Chile, el impacto legal lleva a Ominami (2017) a plantear que falta un pacto constitucional estructurado. Es la misma constitución heredada de la Dictadura: neoliberal, racista y excluyente. Ominami defiende la idea de una constitución legítima para Chile y por ende de una constituyente. Esta reforma central sin lugar a dudas refuerza la democracia en Chile, así como puede plantear nuevos marcos de prevención y lucha contra la corrupción.

\footnotetext{
30. 1. Por el cual se establece un tope de salarios de congresistas y altos funcionarios del Estado. Se hundió el proyecto el 6 de noviembre de 2018 y el 19 de julio de 2019 por decreto presidencial se aumentó el salario de los congresistas. 2. Por medio del cual se regulan las inhabilidades para los condenados por corrupción y delitos contra la administración pública así como la terminación unilateral administrativa del contrato por actos de corrupción y se dictan otras disposiciones. Se hunde en los privilegios de la reclusión para los corruptos; sigue vivo y fue aprobado por la Cámara en la terminación contractual, pero con reservas frente a la posibilidad de ceder el contrato público. 3. Por medio del cual se establecen mecanismos de rendición de cuentas y transparencia de la gestión de los congresistas, diputados, concejales e integrantes de las Juntas Administradoras Locales. Aprobado el 13 de agosto de 2019 con reservas frente a los "pliegos tipo". 4. Por medio del cual se incentiva la transparencia y la participación de los ciudadanos en las decisiones que los afectan en la vida económica, política, administrativa y cultural de la nación y del orden territorial. Aplazado y sin quórum. Radicado nuevamente desde el inicio del proceso legislativo, sin ponentes por el momento. 5. Por medio del cual se busca que los elegidos locales rindan cuentas y elaboren informes de gestión. Aprobado con reservas frente a la agenda pública y el presupuesto realizado en ejercicio de funciones. Pendiente de control por parte de la Corte Constitucional. 6. Por medio del cual se busca garantizar el cumplimiento de los principios de transparencia, participación y control social, mediante la publicación de las declaraciones de bienes, renta y el registro de los conflictos de interés de altos servidores públicos. Aprobado en Senado, falta plenaria Cámara. Se busca presentar reservas frente al registro de conflictos de interés. 7. Por medio del cual se limita la reelección a máximo tres periodos. Se hundió dos veces pero fue radicado de nuevo.
} 


\section{Conclusiones}

Todos los autores citados insisten en el análisis contextual de la corrupción. En Colombia, se hacen evidentes varios frentes: la actualización normativa, la reforma institucional, el cambio cultural. En Chile, se insiste más en la capacitación social sobre la norma y la apropiación local de las políticas de transparencia, gracias a las encuestas de percepción. En este artículo, se subraya el riesgo de un exceso normativo que no se implementa correctamente y se insiste en un enfoque por debajo de la lucha contra la corrupción. Así mismo, se demostró que la sociedad civil cuenta con la capacidad de ejercer un liderazgo político eficaz, de abajo hacia arriba, ya que cuenta con cada vez más recursos para ejercer una presión mayor sobre la administración pública e influenciar los procesos de toma de decisión. La prevención y las dinámicas de cambio cultural, así como un retorno a la ética del funcionario público se hacen primordiales. Tanto en Chile como en Colombia los partidos políticos son llamados a reformarse, con el fin de contener el impacto considerable de la corrupción en la democracia. Estas reformas tienen que ver con una mayor igualdad y transparencia en sus procesos internos. La democracia no es una simple formalidad, sino que debemos entrar en una democracia real basada en la igualdad. Las líneas de investigación que se dibujan a partir de ahora apuntan a la economía política y la sostenibilidad de las políticas de transparencia.

\section{Referencias}

[1] Alianza para el Gobierno Abierto (AGA). (2017). Colombia, hacia un Estado Abierto. Tercer Plan Nacional de Acción 2017-2019. Gobierno de Colombia; ACTUE; FIIAPP; Unión Europea. https://somosmas.org/aga/docs/III-Plan-Colombia_GobAb.pdf

[2] Banco Mundial. (2018a). La pobreza y la prosperidad compartida 2018: Armando el rompecabezas de la pobreza. The World Bank Publications. https://www.oas.org/es/ sadye/documentos/2.pdf

[3] Banco Mundial.(2018b).Piecing Together the Poverty Puzzle. The World Bank Publications. https://openknowledge.worldbank.org/bitstream/handle/10986/30418/9781464813306.pdf

[4] Congreso de la República de Colombia. (1993, 28 de octubre). Ley 80 de 1993. Por la cual se expide el Estatuto General de Contratación de la Administración Pública. Diario Oficial No. 41094. http://www.secretariasenado.gov.co/senado/basedoc/ley_0080_1993.html

[5] Congreso de la República de Colombia. (2000, 15 de agosto). Ley 610 de 2000. Por la cual se establece el trámite de los procesos de responsabilidad fiscal de competencia de las contralorías. Diario Oficial No. 44133. http:/www.secretariasenado.gov.co/ senado/basedoc/ley_0610_2000.html 
[6] Congreso de la República de Colombia. (2011, 12 de julio). Ley 1474 de 2011. Por la cual se dictan normas orientadas a fortalecer los mecanismos de prevención, investigación y sanción de actos de corrupción y la efectividad del control de la gestión pública. Diario Oficial No. 48128. https://www.alcaldiabogota.gov.co/sisjur/normas/Norma1.jsp?i=43292

[7] Congreso de la República de Colombia. (2014, 6 de marzo). Ley 1712 de 2014. Por medio de la cual se crea la Ley de Transparencia y del Derecho de Acceso a la Información Pública Nacional y se dictan otras disposiciones. Diario Oficial No. 49084. https://www.funcionpublica.gov.co/eva/gestornormativo/norma.php?i=56882

[8] Congreso de la República de Colombia. (2015, 6 de julio). Ley Estatutaria 1757 de 2015. Por la cual se dictan disposiciones en materia de promoción y protección del derecho a la participación democrática. Diario Oficial No. 49565. http://www. secretariasenado.gov.co/senado/basedoc/ley_1757_2015.html

[9] Congreso de la República de Colombia. (2016, 2 de febrero). Ley 1778 del 2016. Por la cual se dictan normas sobre la responsabilidad de las personas jurídicas por actos de corrupción transnacional y se dictan otras disposiciones en materia de lucha contra la corrupción. http://es.presidencia.gov.co/normativa/normativa/LEY 1778 DEL 02 DE FEBRERO DE 2016.pdf

[10] Consejo Privado de Competitividad. (s.f.). Informe Nacional de Competitividad 2018-2019. https://compite.com.co/informe/informe-nacional-de-competitividad-2018-2019/\#cpc breadcrumb

[11] Corporación Transparencia por Colombia. (2015). Índice de Transparencia Nacional. Resultados 2013-2014. Comisión Europea; Agencia Presidencial de Cooperación Internacional de Colombia; Ministerio de Educación Nacional. https://bit.ly/3fT13yK

[12] Dahl, R. A. (1994). ¿Después de la revolución? La autoridad en sociedades avanzadas. Gedisa.

[13] De Graaf, G. y Hubert, L. W. J. C. (2008). Portraying the Nature of Corruption Using an Explorative Case Study Design. Diverse Ethical Challenges Facing Today's Public Administrators Public Administration Review, 68(4), 640-653. https://www.jstor.org/stable/25145648

[14] Deneault, A. (2019, 4 de septiembre). Mediocracia, o cómo los mediocres se tomaron el poder. El País. https://elpais.com/elpais/2019/08/30/ideas/1567166223_815812.html

[15] Del Castillo, D. (2019). Diálogos con Robert Alan Dahl. Filosofía de la igualdad política y poliarquía. En H. Rojas (comp.). Manual de historia de las ideas políticas (pp. 193-231). Universidad Externado. https://publicaciones.uexternado.edu.co/manualde-historia-de-las-ideas-politicas-tomo-iv-democracia-finanzas.html

[16] De los Reyes, I. (2015, 16 de enero). "Pentagate”, el caso que destapó la corrupción en Chile. BBC Mundo. https://www.bbc.com/mundo/noticias/2015/01/150115_ chile_caso_penta_corrupcion_irm 
[17] Duarte, O. (2018, 29 de octubre). Los diez departamentos más golpeados por el conflicto en 60 años. El Tiempo. https://www.eltiempo.com/colombia/otrasciudades/cuales-son-los-departamentos-mas-afectados-por-el-conflicto-armadoen-colombia- 286030

[18] Fajnzylber, F. (1990). Industrialización en América Latina: de la "caja negra al casillero vacío”. Comparación de patrones contemporáneos de industrialización. Cuadernos de la CEPAL, 60. https://repositorio.cepal.org/handle/11362/27955

[19] Fiscalía de Chile. (s.f.). Áreas de Persecución - Corrupción. http://www.fiscaliadechile.cl/ Fiscalia/areas/corrupcion.jsp

[20] Gamarra Vergara, J. R. (2006). Pobreza, corrupción y participación política: una revisión para el caso colombiano. Centro de Estudios Económicos Regionales (CEER); Banco de la República.

[21] Garretón, M. A. (2012). Neoliberalismo corregido y progresismo limitado. Los gobiernos de la Concertación en Chile, 1990-2010. Arcis; Clacso; Prospal.

[22] Gobierno de Chile. (1983, 14 de mayo). Ley 18216 de 1983. Establece penas que indica como sustitutivas a las penas privativas o restrictivas de libertad. https:// www.bcn.cl/leychile/navegar?idNorma $=29636$

[23] Gobierno de Chile. (2008, 11 de agosto). Ley 20285 de 2008. Sobre acceso a la información pública. https://www.bcn.cl/leychile/navegar?idNorma=276363

[24] Gobierno de Chile. (2009, 25 de noviembre). Ley 20393 de 2009. Establece la responsabilidad penal de las personas jurídicas en los delitos que indica. https://www.bcn.cl/leychile/navegar?idNorma =1008668\&idVersion=2020-0620\&idParte $=8811454$

[25] Gobierno de Chile. (2014, 3 de marzo). Ley 20730 de 2014. Regula el lobby $\mathrm{y}$ las gestiones que representen intereses particulares ante las autoridades y funcionarios. https://www.bcn.cl/leychile/navegar?idNorma=1060115

[26] González, A. C. y Boehm, F. (2013). Medir la corrupción: de la generación de conciencia a los peligros de la mala interpretación. Revista Ópera, 11, 259-277. https://revistas.uexternado.edu.co/index.php/opera/article/view/3573

[27] La corrupción en Brasil. Internas en Brasil: Jair Bolsonaro designa procurador general a un duro crítico del juez del Lava Jato. (2019, 6 de septiembre). Clarín. https://www.clarin.com/mundo/internas-brasil-jair-bolsonaro-designa-procuradorgeneral-duro-critico-juez-lava-jato_o_hXoiuiTOz.html

[28] Medina, H. F. (2005). Evaluación de impacto de políticas públicas. Políticas presupuestales y gestión por resultados. CEPAL. https://www.academia.edu/53807929/Evaluaci\%C3\%B3n_de_ Impacto_de_Pol\%C3\%ADticas_P\%C3\%BAblicas 
[29] Merat, J. y Roth Deubel, A. N. (2006). La efectividad de las instituciones en la lucha contra la corrupción: la estrategia de los Pactos de Transparencia en Colombia. Revista del CLAD Reforma y Democracia, 36, 1-17. https://www.redalyc.org/pdf/3575/357533668004.pdf

[30] Ministerio de Educación de Colombia -SNIES. (s.f.). Información poblacional. Estadísticas históricas de la educación superior en Colombia. http://hecaa.mineducacion.gov.co/ consultaspublicas/content/poblacional/index.jsf

[31] Lynch (2009). El argumento democrático sobre América Latina. La excepcionalidad peruana en perspectiva comparada. Universidad Mayor de San Marcos.

[32] Monedero, J. C. (2019). Selectividad estratégica del Estado y el cambio de ciclo en América Latina. En H. Ouviña y M. Thwaites Rey (comps.), Estados en disputa. Auge y fractura del ciclo de impugnación al neoliberalismo en América Latina (pp. 338-376). El Colectivo; IEALC; Clacso.

[33] Newman, V. y Ángel, M. P. (2017). Sobre la corrupción en Colombia: marco conceptual, diagnóstico y herramientas de política. Cuadernos de Fedesarrollo, 52. https:/www.repository.fedesarrollo.org.co/handle/11445/3436

[34] Ominami, C. (2018). Chile: el segundo suicidio de la centroizquierda. Nueva Sociedad, 274, 4-12. https://biblat.unam.mx/hevila/Nuevasociedad/2018/no274/1.pdf

[35] Organization for Economic Co-operation and Development (OECD). (2021, March 24). Enhancing economic performance and well-being in Chile: Policy Actions for a more dynamic telecommunication sector. https://www.oecd.org/economy/ surveys/CHL_OECD_policy_actions_dynamic_telecommunication_sector.pdf

[36] Organización para la Cooperación y el Desarrollo Económicos (OCDE). (2017). Estudio de la OCDE sobre integridad en Colombia. Invirtiendo en integridad pública para afianzar la paz y el desarrollo. http://dx.doi.org/10.1787/9789264278646-

[37] Organización para la Cooperación y el Desarrollo Económicos (OCDE). (2018a). Integridad para el buen gobierno en América Latina y el Caribe. Un Plan de Acción. https:// www.oecd.org/latin-america/regional-programme/Integridad-para-el-buengobierno-en-America-Latina-y-el-Caribe-Plan-de-Accion.pdf

[38] Organización para la Cooperación y el Desarrollo Económicos (OCDE). (2018b) Perspectivas de integridad. América Latina y el Caribe 2018. Ficha país Chile. https://www. oecd.org/gov/integridad/ficha-pais-integridad-chile.pdf

[39] Organización para la Cooperación y el Desarrollo Económicos (OCDE). (2018c) Perspectivas de integridad. América Latina y el Caribe 2018. Ficha país Colombia. https:// www.oecd.org/gov/integridad/ficha-pais-integridad-colombia.pdf

[40] Organización para la Cooperación y el Desarrollo Económicos (OCDE). (2019). La integridad pública en América Latina y el Caribe 2018-2019. De gobiernos reactivos a Estados proactivos. https:// www.oecd.org/gov/ethics/integridad-publica-america-latina-caribe-2018-2019.pdf 
[41] Ortiz, M. I. (2019, 10 de julio). Cinco departamentos concentran el $45 \%$ de desaparecidos por conflicto. El Tiempo. https://www.eltiempo.com/justicia/ conflicto-y-narcotrafico/departamentos-con-mas-desaparecidos-por-el-conflictoarmado-en-colombia-386564http://www.secretariatransparencia.gov.co/ secretaria/Documents/DECRETO-1829-DEL-7-DE-NOVIEMBRE-DE-2017.pdf

[42] Palomares, M. (2016). Antecedentes cronológicos de la corrupción y su influencia en la regulación de la Transparencia y el Buen Gobierno en España y Chile. Derecho y Cambio Social, 46, 1-17. https://www.derechoycambiosocial.com/revista046/ ANTECEDENTES_CRONOLOGICOS_DE_LA_CORRUPCION.pdf

[43] Presidencia de la República de Colombia. (2017, 7 de noviembre). Decreto 1829 del 2017. Por el cual se crea el Sistema Integrado de Información para el Posconflicto (SIIPO). Diario Oficial No. 50410. http://www.suin-juriscol.gov.co/viewDocument. asp?ruta=Decretos $/ 30034288$

[44] Rainelli, M. (2010). L'éthique, une nécessité globale. En J. Laroche (dir.), Un monde en sursis. Dérives financières, régulations politiques et exigences éthiques (pp. 77-89). L'Harmattan.

[45] Rodríguez, M. y Sarthou, N. (2008). La noción de "rendición de cuentas" aplicada a un instrumento internacional contra la corrupción. Debates Latinoamericanos, 6(11). https://revistas.rlcu.org.ar/index.php/Debates/article/view/130/104

[46] Rojas, H. (comp.). Manual de historia de las ideas políticas. Universidad Externado. https:// publicaciones.uexternado.edu.co/manual-de-historia-de-las-ideas-politicas-tomo-ivdemocracia-finanzas.html

[47] Salinero Echeverría, S. (2012). ¿Por qué aumenta la población penal en Chile? Un estudio criminológico longitudinal. Ius et Praxis, 18(1), 113-150. http://dx.doi. org/10.4067/S0718-00122012000100005

[48] Secretaría de Transparencia. (s.f.). Marco Normativo. http://www.secretariatransparencia. gov.co/secretaria/Paginas/marco-normativo.aspx

[49] Segunda orden de captura contra Carlos Mattos. (2019, 17 de julio). Revista Semana. https://www.semana.com/nacion/articulo/segunda-orden-de-captura-contracarlos-mattos/623927

[50] Unidad Investigativa. (2020, 31 de mayo). Disidencias de las Farc duplican su número de hombres en solo 12 meses. El Tiempo. https://www.eltiempo.com/unidad-investigativa/ disidencias-de-las-farc-duplican-su-numero-de-hombres-en-armas-solo-12-meses-501426

[51] Valdivieso, P., Bernas, J. y Ganga, F. (2014). Una mirada constructiva para la política de "transparencia activa”, caso chileno. Documentos y Aportes en Administración Pública y Gestión Estatal, 14(22), 45-70. https://www.redalyc.org/articulo.oa?id=337531584002 